\title{
ESCALPE E EQUIPO DE SORO: \\ Opinião de enfermeiras quanto aos requisitos essenciais de qualidade
}

\author{
Sayuri Tanaka Maeda * \\ Maria Coeli Campedelli ${ }^{k *}$
}

RESUMO - Este trabalho é parte do estudo que foi realizado por MAEDA $^{7}$ (Dissertação de Mestrado - EEUSP - 1988), em seis hospitais públicos da Secretaria de Estado da Saúde de São Paulo. Utilizou-se um formulário especifico como instrumento de coleta de dados do qual, para o presente estudo, foi computado somente uma questão. O formulário foi aplicado a 75 enfermeiras. A população entrevistada demonstrou ter conhecimentos suficientes dos critérios de qualidade do escalpe e equipo de soro para subsidiar a compra.

ABSTRACT - This work is part of the study which was made by Maeda (Dissertação de EEUSP 1988 - Essay for M.A. - 1988), in six public hospital of the Secretaria de Estado da Saúde de São Paulo. A specific form was used as an instrument to collect data, only one question of which having been computed for the present study. The form was applied to 75 nurses. The people interviewed showed to have enough knowledge of the quality criterea of the "butterfley needle" and "infusion set" to subsidize the purchase.

\section{INTRODUÇÃO}

O Serviço de Enfermagem utiliza a maior parte dos materiais hospitalares e, portanto, essa categoria tem a necessidade de opiniar sobre a aquisição de materiais de qualidade e em quantitade condizentes com as necessidades do atendimento.

Nossa vivência tem demonstrado que o hábito de fixar critérios de qualidade que norteiem a escolha de determinados materiais ainda não ocorre de forma efetiva. $\mathrm{Na}$ ausência desses, as escolhas são baseadas em experiências individuais, preferência por marcas, subjetividades e apenas na inspeção visual, para emitir pareceres técnicos quanto à qualidade, segurança e eficiência.

RIBEIRO $^{8}$, elaborou um procedimento com o objetivo de qualificar e possibilitar a escolha de Sondas Descartáveis para aspiração traqueal pela fixação de caracteres mínimos necessários, num trabalho apresentado no Congresso Nacional de Cirurgia Toráxica em 1985. Tal procedimento está sendo utilizado pela Comissão de Especificação de Materiais do Hospital das Clinicas da Faculdade de Medicina da Universidade de São Paulo (FMUSP). Depreende-se ser este estudo uma importante fonte de conhecimento para os profissionais de enfermagem preocupados com a aquisição de materiais.

COSTA $^{5}$ apresentou um plano de atuação da(o) enfermeira(o) da Comissão Técnica de Corr- pras, no qual utilizou a experimentação prévia como condição fundamental para aprovação ou rejeição dos materiais. Durante o perfodo de testes, as observações feitas pelas(os) enfermeiras(os) foram anotadas em fichas e, posteriormente, utilizadas para análise e comparação de variação. SECAF $^{\circ}$ descreve a sua experiência como enfermeira participante da Comissão Técnica de Compras da Divisão de Material (órgão extinto) do Instituto Nacional de Previdência e Assistente Social (INAMPS) da Regional de São Paulo:

Um outro fator que dificulta a aquisição adequada de materiais em uma Instituição é a falha na comunicação entre o Serviço de Enfermagem e o Serviço de Material. Este, mesmo se inteirando das repercussões da falta de måterial na assistência de enfermagem, às vezes não consegue adquirir os materiais em tempo hábil, quer pelo atraso na entrega do produto, quer pela não disponibilidade nos setores de produção industrial. Concomitantemente a isto, a má qualidade dos produtos e a inadequação dos materiais adquiridos acabam criando "stress" nos elementos da equipe de enfermagem, principalmente nas situações de emergência.

ARAÚJO' fornece subsídios importantes a todas as pessoas interessadas em materiais, quer no Serviço de Enfermagem, quer no Serviço de Material, enfocando o planejamento, a organi-

* Enfermeira assessora do Grupo Gerente de Hospitais da Secretaria de Saúde do Estado de São Paulo.

** Enfermeira Prof" Doutora do Departamento de Enfermagem Médico-Cinírgica da Escola de Enfermagem da USP. 
zação e o controle como fatores fundamentais para a aquisição, guarda e distribuição dos produtos.

A falta de comunicação agrava a situação da enfermagem quando, frente à necessidade de executar os procedimentos de assistência, depara-se por exemplo com equipos de soro apresentando defeitos de fabricação, tais como: válvulas reguladoras de gotejamento que não funcionam, vazamento nas conexões e com escalpe, agulhas que desconectam da asa.

Nas várias oportunidades em que uma das autoras participou do julgamento de materiais, levava a indagações tais como:

" Como eu vou escolher ? Com que parâmetros vou justificar a escolha? Porque o material X é melhor do que o Y" ? Devo por optar por este material, pois não tenho encontrado problemas no uso ..."?

Mediante tais indagações, sabia-se que a decisão dependia muito mais da experiência de cada profissional, do que de critérios que justificassem a escolha.

Os exemplos são múltiplos: houve relato de experiếncia como ao ser usado escalpe em uma criança, a agulha desconectou do corpo da asa acarretando problemas que poderiam ter sido mais graves, caso a atuação da enfermeira não fosse imediata, impedindo-se que a cânula penetrasse na corrente sangǘnea. Naturalmente $o$ elemento responsável pela aquisição do material deveria imediatamente tomar conhecimento dessa problemática, face a futuras licitações, perante o risco a que o paciente ficou submetido.

Não é frequiente existir um esquema sistematizado de testes comparativos entre marcas diferentes e o registro documental de tais testes. Às vezes, mesmo quando realizados, não são convenientemente registrados para oferecer subsídios para futuras compras. Tais fatos acarretam problemas, pois a enfermagem recebe materiais de má qualidade, mesmo conhecendo a existência de outros que respondem melhor às necessidades do momento.

$\mathrm{Na}$ prática, entretanto, tem-se conhecimento de que, em alguns centros hospitalares mais avançados, existem mecanismos de integração da enfermagem com o setor de compras. Um dos mecanismos é a presença de enfermeiras(os) trabalhando nessa área e implantando sistemas de informações quanto às especificações e testes necessários para qualificar equipamentos hospitalares, quer materiais de consumo quer materiais permanentes.

Os materiais hospitalares denominados materiais de consumo são apresentados no mercado numa diversidade muito grande quanto aos tipos e qualidade. ELKIS ${ }^{6}$ aborda o papel dos materiais descartáveis e enfatiza que estes constituem um avanço tecnológico em prol da segurança, da garantia de esterilidade e da elimi- nação de riscos para o paciente. Além disso, permitem maior agilização do trabalho e eficiência por estarem disponf́veis para uso imediato, desde que suas caracteristicas físicas e quimicas sejam rigorosamente controladas durante o processo da fabricação. Regra geral, esse controle não deve estar ocorrendo, visto não se dispor ainda, na Associação Brasileira de Normas Técnicas (ABNT), de normas especfficas de exigência de qualidade de produção para a maioria dos materiais hospitalares, ou mesmo de fiscalização rigorosa. $\mathrm{O}$ que fazer, por exemplo, com a atadura de gesso que, quando aplicada, não seca no tempo previsto ?

A presença de materiais defeituosos no mercado nacional pode ser reflexo da ausência de normas técnicas; cujo não cumprimento seja passivel de sanção, relativas a muitos materiais de uso hospitalar, como meio efetivo de disciplinar as empresas fabricantes. Conforme consultas no Instituto de Pesquisas Tecnológicas de São Paulo (IPT), essa falta de normatização não ocorre em outros parses porque estes possuem órgãos como o ISO (Internacional Standards Office), o JIS (Japanese Industrial Standards), o DIN (Desutsches Institut fur Normung) e outros, aos quais é obrigatória a consulta para fabricação de qualquer material. Esses órgãos se tomam, portanto, padronizadores da produção $e$ reguladores de mercado.

Elaborar criterios de qualidade constitui-se na fase inicial de um ciclo de inspeção de qualidade pois precederia as demais fases do processo, tais como: testes, documentação de fatos observados, análise dos dados e aprovação ou rejeição de materiais. Qualquer produto, por mais simples que seja apresenta grande número de características de qualidade. Não sendo possível considerá-las a todas, deve-se ater aos requisitos que determinam pelo menos a praticidade e exequiibilidade SMITH ${ }^{10}$.

\section{OBJETIVOS}

Levantar as 'ópınıoes das(os) Enfermeiras(os) e Enfermeira-Chefe/Diretora quanto aos requisitos essenciais de qualidade dos materiais de consumo: escalpe e equipo de soro.

\section{METODOLOGIA}

Dos 24 hospitais mantidos pela Secretaria de Estado da Saúde de São Paulo foram escolhidos para este estudo seis hospitais, pela similaridade de sua organização administrativa. Desses, quatro estão localizados na Capital, um na Grande São Paulo - Ferraz de Vasconcelos e outro localiza-se em Santos.

Para a coleta de dados, foi utilizado um instrumento específico (Anexo I) para o pre- 
sente estudo, que só teve computado os dois primeiros itens da 5a questão.

Dado o número elevado de especificidade desses materiais, tomou-se como gabarito as normas - Agulhas hipodérmicas estéreis e de uso único: especificação: NBR 9259², Cânula de escalpe: identificação do calibre por cor: NBR $9753^{3}$ e a última Comissão de Estudos de Seringas e Agulhas. Equipo de transfusão, estéril e de uso único: projeto $\mathrm{n}-04: 12.1-00^{4}$.

A população pesquisada constituiu-se de 75 enfermeiras(os) e 13 Chefes de Seção/Serviço de Enfermagem.

Foram estabalecidos como critérios para fazer parte da pesquisa:

- ser enfermeira(o) de plantão diurno;

- estar em exerć́cio efetivo há 2 anos ou mais na profissão.

Em cada uma das seis Instituições entrevistaram-se as Diretoras e Chefes de Serviço de Enfermagem e 10 Enfermeiras(os) que preencheram os critérios estipulados.

Para a inclusão das(os) Enfermeiras(os) na pesquisa, obedeceu-se ao método de sorteio que foi realizado mediante uma listagem fornecida pela Chefia de Enfermagem.

A coleta de dados foi realizada entre 31 de outubro de 1987 a 31 de dezembro de 1987 por uma enfermeira treinada especificamente para esta atividade.

\section{Apresentação e Análise dos Resultados}

Os resultados relacionados à questão número 5 no que se refere ao escalpe e equipo de soro poderão ser observados em oito tabelas. Nessas Tabelas serão utilizadas a nomenclatura adotada pela ABNT, com a finalidade de apresentar os resultados conforme as normas estabelecidas.

Convenciou-se adotar o patamar de $40 \%$ e/ou mais respostas obtidas, a fim de selecionar requisitos de qualidade dos materiais propostos para o estudo, considerando:

- o número de características indicadas relativamente grande para itens de qualidade,

- o estabelecimento do valor estipulado em $40 \%$ serve de divisor, que corresponde aos quesitos mais indicados por grupos;

- a pergunta por ser aberta, dá margens aos entrevistados de se expressarem livremente quanto às características de qualidade.

Apresentaremos a seguir as tabelas 1, 2, $3 \mathrm{e}$ 4, que indicam as características de qualidade identificadas pelos grupos de Enfermeiras(os) e Enfermeiras - Chefe/Diretora, quanto ao ESCALPE.

Tabela 1 - Distribuição das características de qualidade indicadas pelas(os) Enfermeiras(os) e Enfermeiras-Chefe/Diretora dos Hospitais governamentais em relação aos componentes (Bisel, Cânula e Protetor de Cânula , do escalpe. São Paulo, 1987.

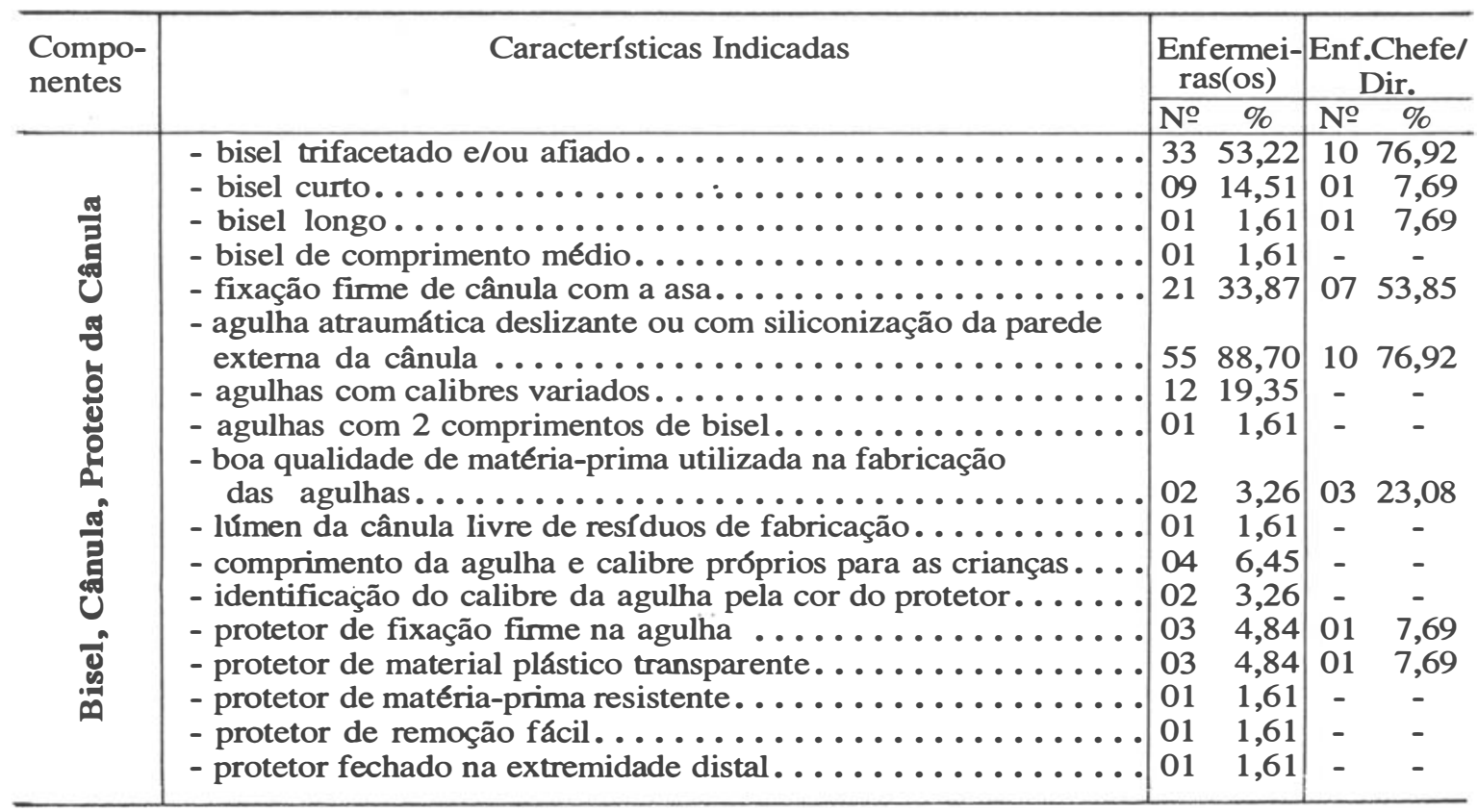


Tabela 2 - Distribuição das características de qualidade indicadas pelas(os) Enfermeiras(os) e Enfermeira-Chefe/Diretora . dos hospitais governamentais em relação aos componentes (Asa e Tubo flexível), do escalpe. São Paulo, 1987.

\begin{tabular}{|c|c|c|c|c|}
\hline \multirow[t]{2}{*}{$\begin{array}{l}\text { Compo- } \\
\text { nentes }\end{array}$} & \multirow[t]{2}{*}{ Características Indicadas } & \multicolumn{2}{|c|}{$\begin{array}{c}\text { Enfermei- } \\
\text { ras(os) }\end{array}$} & $\begin{array}{c}\text { Enf.Chefe/ } \\
\text { Dir. }\end{array}$ \\
\hline & & № & $\%$ & № $\%$ \\
\hline \& & 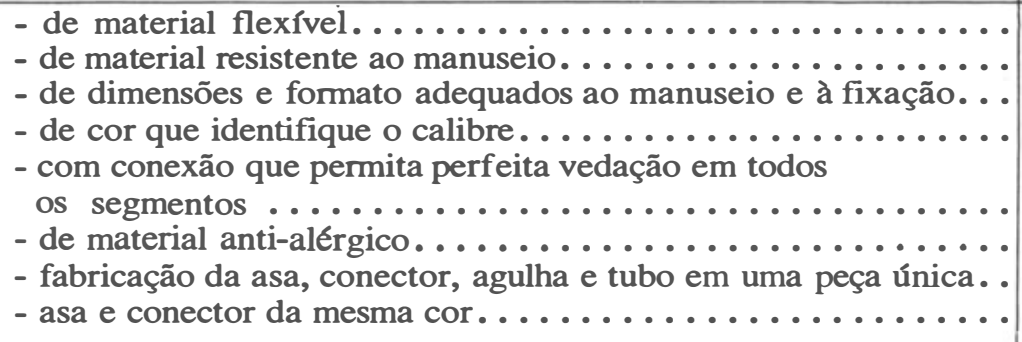 & $\begin{array}{l}39 \\
27 \\
17 \\
13 \\
02 \\
- \\
01 \\
01\end{array}$ & $\begin{array}{l}62,90 \\
43,54 \\
27,42 \\
20,96 \\
3,26 \\
- \\
1,61 \\
1,61\end{array}$ & $\begin{array}{cc}13 & 100,00 \\
04 & 30,77 \\
09 & 69,23 \\
02 & 15,38 \\
03 & 23,07 \\
01 & 7,69 \\
- & - \\
- & -\end{array}$ \\
\hline 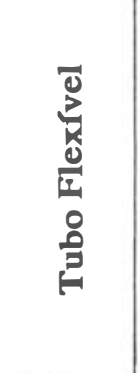 & 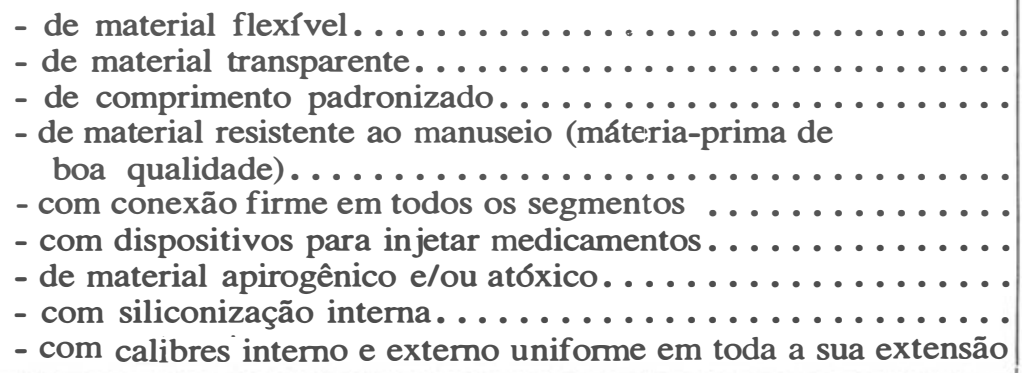 & $\begin{array}{c}06 \\
03 \\
03 \\
02 \\
01 \\
-\end{array}$ & $\begin{array}{r}59,68 \\
45,16 \\
22,58 \\
9,68 \\
4,84 \\
4,84 \\
3,25 \\
1,61 \\
-\end{array}$ & $\begin{array}{cc}10 & 76,92 \\
09 & 69,23 \\
01 & 7,69 \\
& \\
02 & 15,38 \\
01 & 7,69 \\
- & - \\
- & - \\
- & - \\
01 & 7,69\end{array}$ \\
\hline
\end{tabular}

Tabela 3 - Distribuição das características de qualidade indicadas pelas(os) Enfermeiras(os) e Enfermeira-Chefe/Diretora dos hospitais governamentais em relação aos componentes (Conector e Tampa do Conector), do escalpe. São Paulo, 1987

\begin{tabular}{|c|c|c|c|}
\hline \multirow[t]{2}{*}{$\begin{array}{l}\text { Compo- } \\
\text { nentes }\end{array}$} & \multirow[t]{2}{*}{ Caracterf́sticas Indicadas } & $\begin{array}{c}\text { Enfermei- } \\
\operatorname{ras}(o s)\end{array}$ & $\begin{array}{c}\text { Enf.Chefe/ } \\
\text { Dir. }\end{array}$ \\
\hline & & $\begin{array}{ll}\text { No } & \%\end{array}$ & № $\%$ \\
\hline 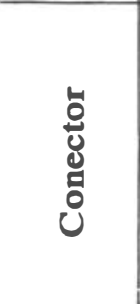 & 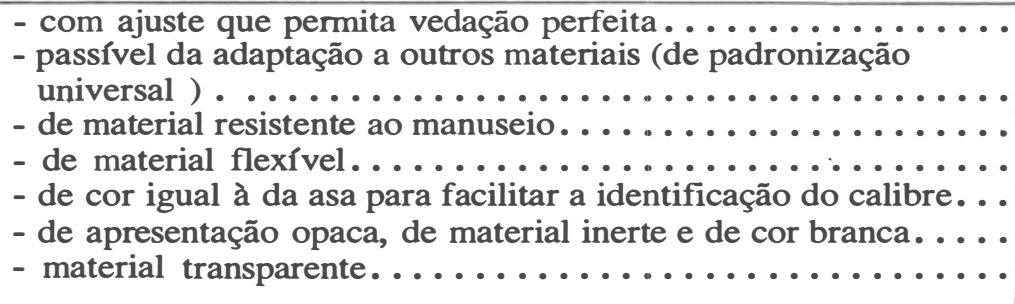 & $\mid \begin{array}{cc}23 & 37,10 \\
12 & 19,35 \\
09 & 14,52 \\
02 & 3,25 \\
- & - \\
01 & 1,61 \\
01 & 1,61\end{array}$ & $\begin{array}{lc}07 & 53,85 \\
06 & 46,15 \\
04 & 30,77 \\
01 & 7,69 \\
01 & 7,69 \\
- & - \\
- & -\end{array}$ \\
\hline 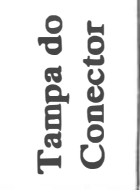 & 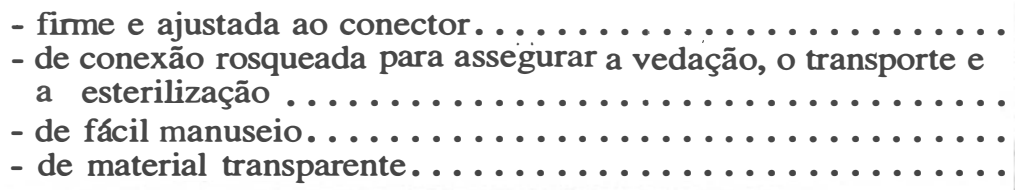 & $\begin{array}{rr}26 & 41,93 \\
07 & 11,29 \\
04 & 6,45 \\
01 & 1,61\end{array}$ & $\begin{array}{cc}03 & 23,08 \\
03 & 23,08 \\
03 & 23,08 \\
-\quad-\end{array}$ \\
\hline
\end{tabular}


Tabela 4 - Distribuição das caracteristicas de qualidade indicadas pelas(os) Enfermeiras(os) e Enfermeira-Chefe/Diretora . dos Hospitais governamentais em relação aos componentes (Embalagens), do escalpe. São Paulo, 1987.

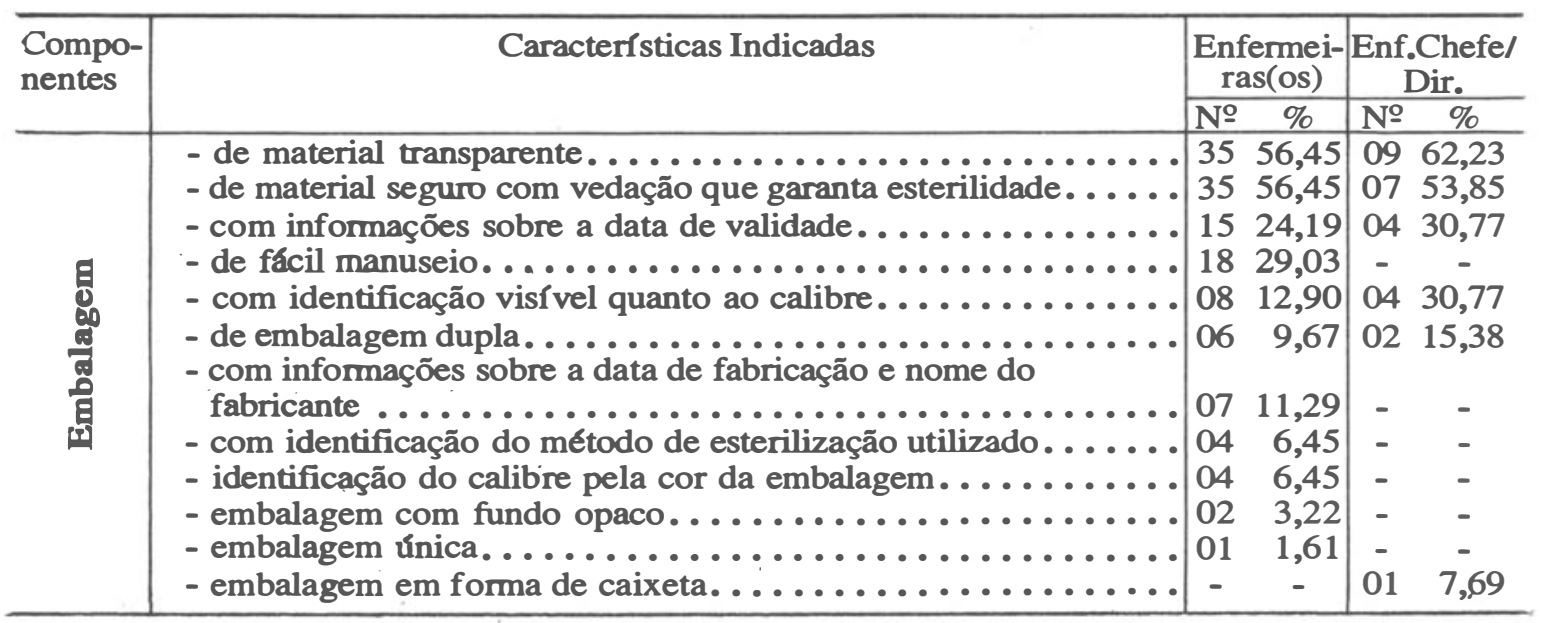

No grupo de Enfermeiras(os) verifica-se que as características de qualidade indicadas por mais de $40 \%$ para o escalpe, são as seguintes:

- agulha atraumática deslizante ou com siliconização da parede externa da cânula;

- asa de material flexível;

- tubo flexível de material flexível;

- embalagem de material transparente;

- embalagem de material seguro com vedação que garanta a esterilidade;

- bisel trifacetado e/ou afiado;

- tubo flexível de material transparente;

- asa de material resistente ao manuseio;

- tampa de conector firme e ajustada ao conector.

Entre as Enfermeiras-Chefe/Diretora as características indicadas por mais de $40 \%$ são as seguintes:

- asa de material flexível;

- bisel trifacetado e/ou afiado;

- agulha atraumática deslizante ou com siliconização da parede externa da cânula;

- tubo flexível de material flexível;

- tubo flexível de material transparente;

- asa de dimensões e formato adequados ao manuseio e à fixação;

- embalagem de material transparente;

- embalagem de material seguro com vedação que garanta a esterilidade;

- conector com ajuste que permita a vedação perfeita;

- fixação firme de cânula com a asa;

- conector passível de adaptação a outros materiais (padronização universal).
Em relação ao escalpe foi constatado um número maior de características, em ambos os grupos, do que o esperado. Considerando as características acima de $40 \%$ de freqüência, verificaram-se nove itens no grupo de enfermeiras(os) e 11 no das Enfermeiras-Chefe/Diretora, conforme Tabelas 1, 2, 3 e 4. Dentre as características citadas por grupos de Enfermeiras-Chefe/Diretora houve sete características comuns dentro do percentual proposto de $40 \%$.

Cabe salientar que no grupo das Enfermeiras-Chefes/Diretora os quatro aspectos "fixação firme das cânulas com asa", 53,85\%, "asa de dimensão e formato adequado ao manuseio e à fixação", 69,23\%, "conector com ajuste que permita a vedação perfeita", 53,85\%, e "conector passível de adaptação a outros materiais (padronização universal)", 46,15\%, não atingiram o percentual estipulado no grupo das Enfermeiras(os). E, "asa de material resistente ao manuseio", $43,54 \%$, citado por este grupo, contra $30,77 \%$ do grupo das Enfermeiras-Chefe/Diretora; outra característica indicada foi "tampa do conector firme ajustada ao conector", por $41,93 \%$ das Enfermeiras, contra $23,08 \%$ das Enfermeiras-Chefe-Diretora.

Ao analisar as tabelas referentes às características do Escalpe podemos ainda observar que:

Comparando-se as características indicadas pelas(os) Enfermeiras(os) e Enfermeiras-Chefe/Diretora com a Norma NBR 9753 e NBR 9259 da ABNT, observou-se que esses profissionais somente deixaram de indicar a seguinte especificacáo: "sobre a parte plana da asa deve estar 
marcado o símbolo do fabricante de diâmetro nominal e ou cânula". No entanto, citaram vários aspectos que não se enquadram em normas previstas, tais como: "agulhas de calibre variado . ..." "embalagem em forma de caixeta", entre outras.

Pelas observações esquematizadas nas Tabelas $1,2,3$ e 4 verifica-se, dado ao número importante de características levantadas, que essas profissionais são conhecedores das características fundamentais de qualidade do escalpe, embora tenha sido pouco lembrada uma características de suma importância, que é o protetor de cânula.

Apresentaremos, a seguir, as especificações do escalpe dentro do percentual estipulado para o presente estudo, mediante opiniōes levantadas pelas(os) Enfermeiras(os) e Enfermeiras - Chefe/Diretoras entrevistadas (Fig. 1).

Quanto às características do EQUIPO DE SORO relacionadas pelas(os) Enfermeiras(os) e Enfermeiras - Chefe/Diretora, estão indicadas nas Tabelas 5, 6, 7 e 8.

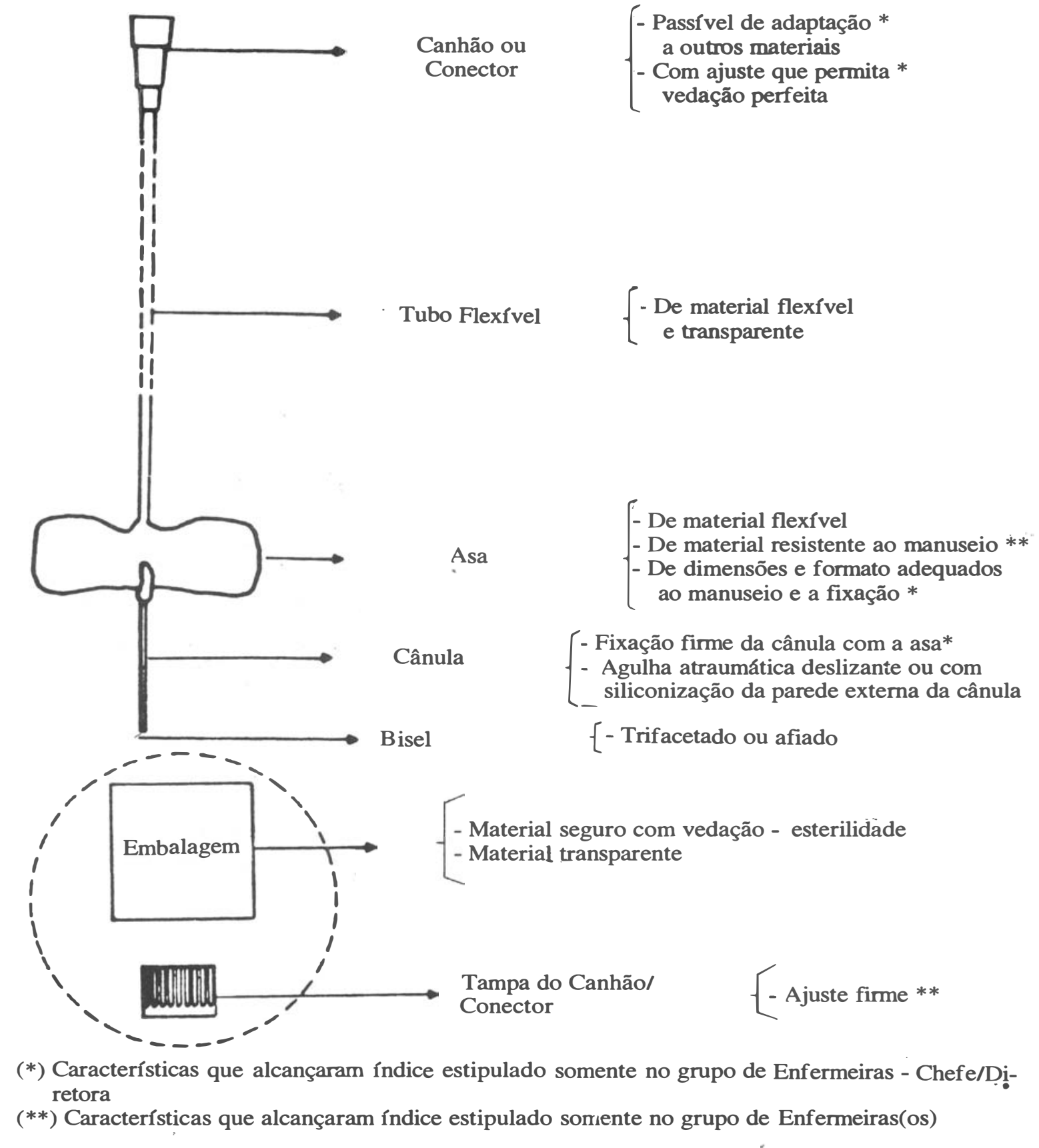

FIGURA 1 - ESCALPE 
Tabela 5 - Distribuição das características de qualidade indicadas pelas(os) Enfermeiras(os) e Enfermeiras - Chefe/Diretora dos hospitais governamentais em relação aos componentes (Câmara de Gotejamento, Gotejador, perfurador e seu Protetor), do equipo de soro. São Paulo, 1987.

\begin{tabular}{|c|c|c|c|c|c|}
\hline \multirow[t]{2}{*}{$\begin{array}{l}\text { Compo- } \\
\text { nentes }\end{array}$} & \multirow[t]{2}{*}{ Características Indicadas } & \multicolumn{2}{|c|}{$\begin{array}{c}\text { Enfermei- } \\
\text { ras(os) }\end{array}$} & \multicolumn{2}{|c|}{$\begin{array}{c}\text { Enf.Chefe/ } \\
\text { Dir. }\end{array}$} \\
\hline & & № & $\%$ & & \\
\hline 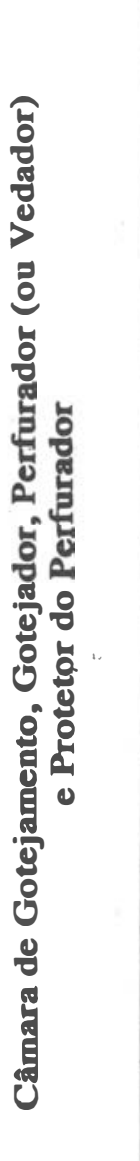 & 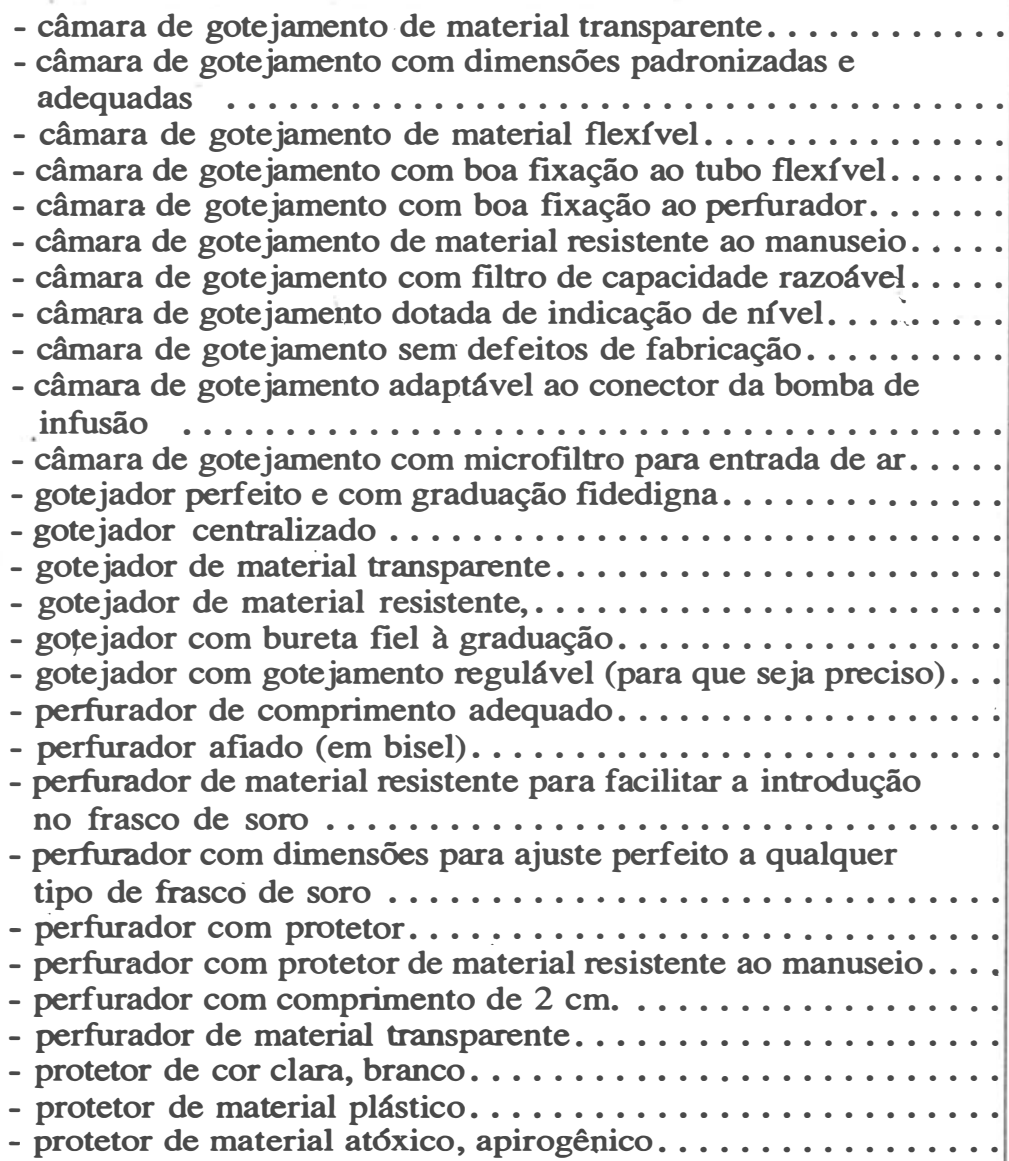 & $\begin{array}{l}01 \\
01 \\
02 \\
15 \\
- \\
01 \\
02 \\
02 \\
05 \\
35\end{array}$ & $\begin{array}{r}70,97 \\
22,58 \\
9,68 \\
8,06 \\
8,06 \\
6,45 \\
1,61 \\
1,61 \\
1,61 \\
1,61 \\
1,61 \\
3,25 \\
24,19 \\
- \\
1,61 \\
3,22 \\
3,25 \\
8,06 \\
56,45 \\
\\
50,00 \\
50,00 \\
8,06 \\
3,25 \\
- \\
- \\
- \\
1,61 \\
1,61\end{array}$ & $\begin{array}{c}- \\
- \\
06 \\
03 \\
03 \\
01 \\
01 \\
- \\
03 \\
09\end{array}$ & $\begin{array}{c}76,92 \\
23,07 \\
- \\
- \\
- \\
7,69 \\
- \\
- \\
- \\
\\
- \\
- \\
46,15 \\
23,07 \\
23,07 \\
7,69 \\
7,69 \\
- \\
23,07 \\
69,23 \\
61,35 \\
40,15 \\
- \\
15,38 \\
7,69 \\
7,69 \\
7,69 \\
- \\
-\end{array}$ \\
\hline
\end{tabular}


Tabela 6 - Distribuição das características de qualidade indicadas pelas(os) Enfermeiras(os) e Enfermeira-Chefe/Diretora dos hospitais governamentais em relação aos componentes (Tubo flexível e Área para injeção de medicamentos), do equipo de soro. São Paulo, 1987.

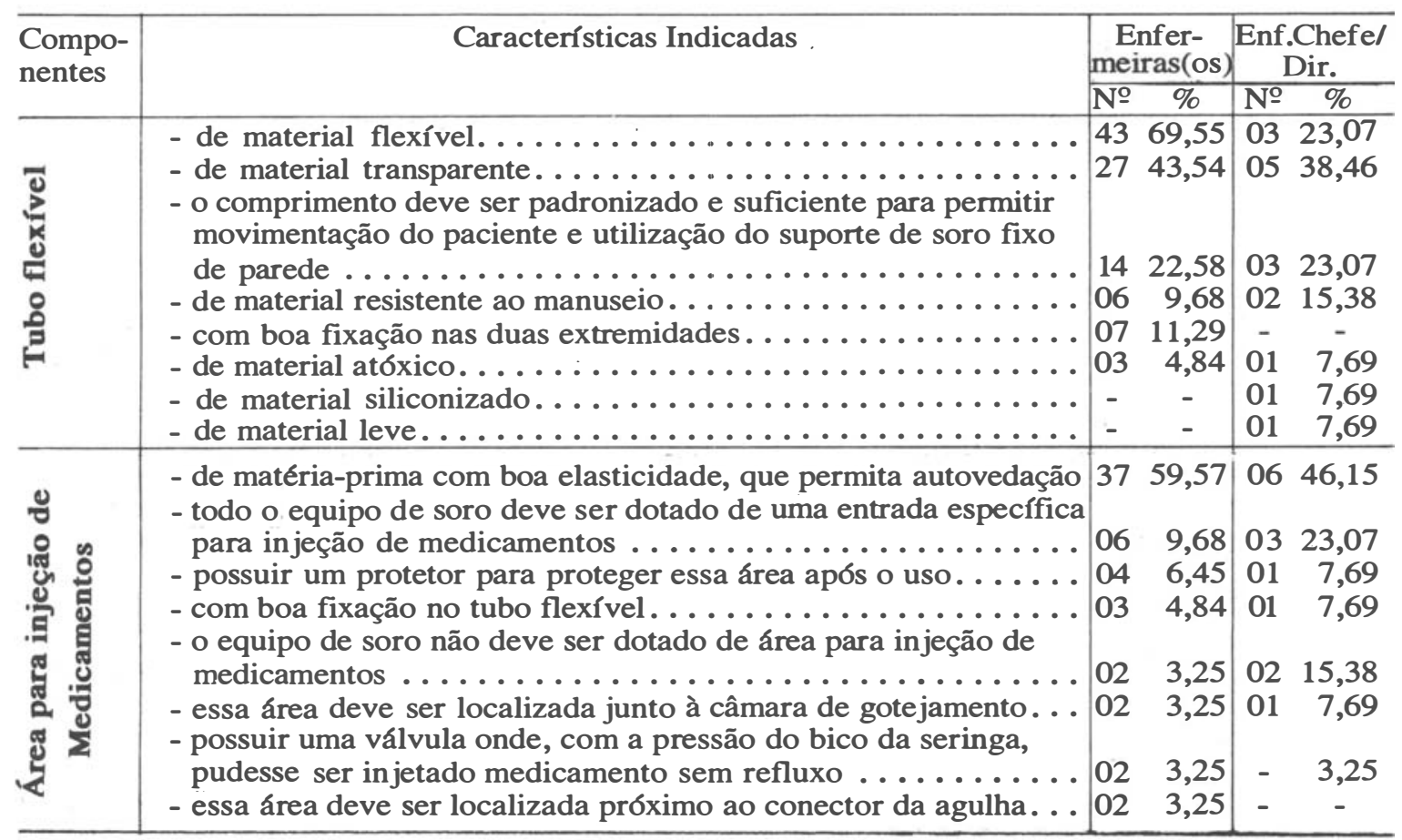

Tabela 7 - Distribuição das características de qualidade indicadas pelas(os) Enfermeiras(os) e Enfermeira-Chefe/Diretora dos hospitais governamentais em relação aos componentes (Conector e Regulador de Fluxo), do equipo de soro. São Paulo, 1987.

\begin{tabular}{|c|c|c|c|c|}
\hline \multirow[t]{2}{*}{$\begin{array}{l}\text { Compo- } \\
\text { nentes }\end{array}$} & \multirow[t]{2}{*}{ Características Indicadas } & \multicolumn{2}{|c|}{$\begin{array}{c}\text { Enfer- } \\
\text { meiras(os) }\end{array}$} & \begin{tabular}{|c|} 
Enf.Chefe/ \\
Dir.
\end{tabular} \\
\hline & & No & $\%$ & № \\
\hline 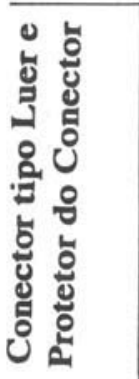 & 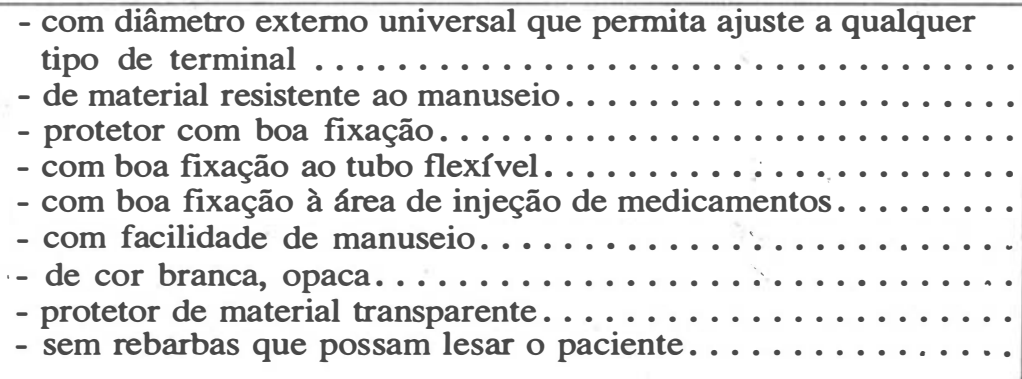 & $\begin{array}{l}29 \\
07 \\
11 \\
09 \\
01 \\
01 \\
02 \\
11 \\
01\end{array}$ & $\begin{array}{c}46,77 \\
11,29 \\
17,74 \\
14,52 \\
1,61 \\
1,61 \\
3,25 \\
- \\
1,61\end{array}$ & $\begin{array}{cc}09 & 69,23 \\
05 & 38,46 \\
- & - \\
01 & 7,69 \\
02 & 15,38 \\
01 & 7,69 \\
- & 7,69 \\
02 & 15,38 \\
- & -\end{array}$ \\
\hline 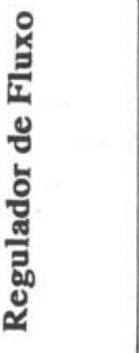 & 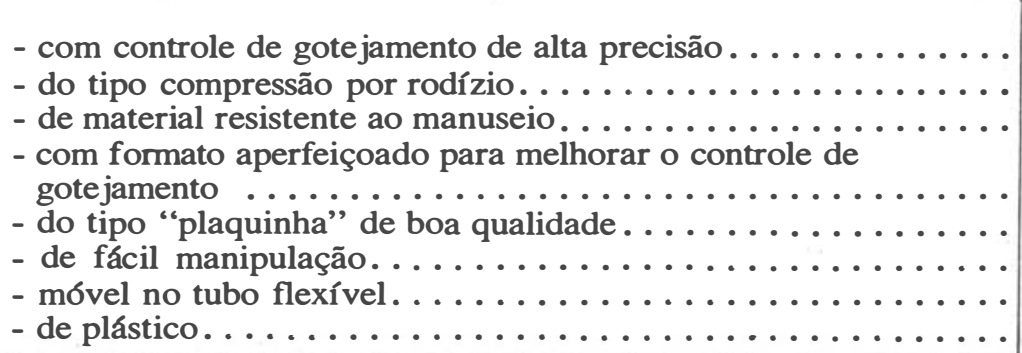 & $\begin{array}{l}53 \\
15 \\
14 \\
05 \\
04 \\
02 \\
01 \\
01\end{array}$ & $\begin{array}{r}85,48 \\
24,19 \\
22,58 \\
\\
8,06 \\
6,45 \\
3,25 \\
1,61 \\
1,61\end{array}$ & $\begin{array}{ll}08 & 61,53 \\
03 & 23,07 \\
02 & 15,38 \\
- & - \\
- & - \\
- & - \\
- & - \\
- & -\end{array}$ \\
\hline
\end{tabular}


Tabela 8 - Distribuição das características de qualidade indicadas pelas(os) Enfermeiras(os) e - e Enfermeiras - Chefe/Diretora dos hospitais governamentais em relação ao componente (Embalagem), do equipo de soro. São Paulo, 1987.

\begin{tabular}{|c|c|c|c|c|}
\hline \multirow[t]{2}{*}{$\begin{array}{l}\text { Compo- } \\
\text { nentes }\end{array}$} & \multirow[t]{2}{*}{ Características Indicadas } & \multicolumn{2}{|c|}{$\begin{array}{c}\text { Enfer- } \\
\text { meiras(os) }\end{array}$} & \begin{tabular}{|c} 
Enf.Chefel \\
Dir.
\end{tabular} \\
\hline & & & $\%$ & \\
\hline 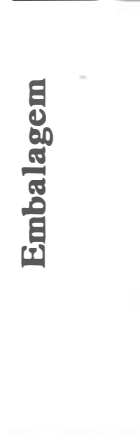 & 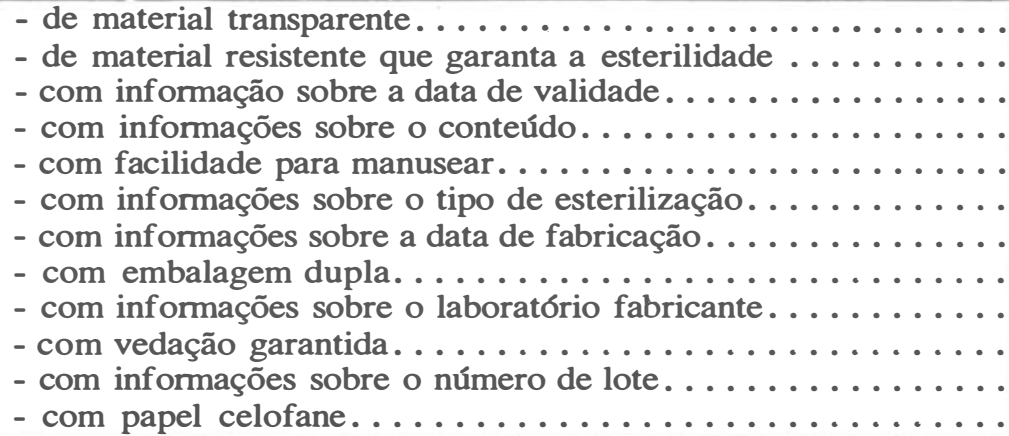 & $\begin{array}{l}30 \\
20 \\
15 \\
12 \\
09 \\
05 \\
02 \\
04 \\
- \\
01 \\
01 \\
01\end{array}$ & $\begin{array}{r}48,38 \\
32,25 \\
24,19 \\
19,35 \\
14,51 \\
8,06 \\
3,25 \\
6,45 \\
- \\
1,61 \\
1,61 \\
1,61\end{array}$ & $\begin{array}{cc}07 & 53,84 \\
06 & 46,15 \\
06 & 46,15 \\
04 & 30,76 \\
01 & 7,69 \\
- & - \\
02 & 15,38 \\
- & - \\
02 & 15,38 \\
01 & 7,69 \\
- & - \\
- & -\end{array}$ \\
\hline
\end{tabular}

No grupo de Enfermeiras(os) verifica-se que as características de qualidade indicadas, por mais de $40 \%$ para o equipo de soro, são as seguintes:

- regulador de fluxo com controle de gotejamento de alta precisão; parente;

- câmara de gotejamento de material trans-

- tubo flexível de material flexível;

- área para injeção de medicamentos de matéria-prima com boa elasticidade que permita auto-vedação;

- perfurador afiado (em bisel);

- perfurador de material resistente para facilitar a introdução no frasco de soro;

- perfurador com dimensões para ajuste perfeito a qualquer tipo de soro;

- embalagem de material transparente;

- conector tipo Luer com diâmetro externo universal que permita ajuste a qualquer tipo de terminal;

- tubo flexível de material transparente.

Entre as Enfermeiras-Chefe/Diretora as características de qualidade indicadas por mais de $40 \%$ são as seguintes:

- câmara de gotejamento de material transparente;

- conector tipo Luer com diâmetro externo universal que permita ajuste a qualquer tipo de material;

- perfurador afiado (em bisel);

- perfurador de material resistente para faci-

litar a introdução no frasco de soro;

- regulador de fluxo com controle de gotejamento de alta precisão;

- embalagem de material resistente que garanta a esterilidade;

- embalagem com informações sobre a data de validade;

- área para injeção de medicamentos de matéria-prima com boa elasticidade, que permita auto-vedação;

- perfurador com dimensões para ajuste perfeito a qualquer tipo de frasco de soro; digna.

- gotejador perfeito e com graduação fide-

Algumas características encontradas não foram computadas como componente do equipo de soro, pois se referiam ao Equipo de soro como um conjunto. São elas:

- como método de esterilização confiável;

- possuir buretas para o controle;

- ser de material opaco e escuro para medicação fotossensível.

Considerando as características acima de $40 \%$ de frequência, verificaram-se 10 itens do grupo de Enfermeiras(os) e 11 no das Enfermeiras-Chefe/Diretora, conforme as tabelas 5, 6, 7 e 8. Praticamente não houve diferença entre os grupos em termos quantitativos, porém o grupo de Enfermeiras(os) se comparando com o de Enfermeiras-Chefe/Diretora, dentro da porcentagem considerada para o presente estudo, não identificou: "gotejador perfeito e fidedigno", aspectos de embalagem como "de material resistente que garanta a esterilidade" e "com informações sobre a data de validade" e "gote jador perfeito com graduação fidedigna”.

Por outro lado, as características "tubo flexível de material flexível" e "de material transparente" foram citadas por mais de $40 \%$ da população de Enfermeiras(os) entrevistadas(os). Contudo, a primeira foi lembrada por três das treze Enfermeira-Chefe/Diretora correspondendo a $23,07 \%$, e a segunda, "tubo flexível de material transparente", foi indicada por cinco dessas profissionais, correspondendo a $38,46 \%$. Cabe ainda ressaltar que o "conector tipo Luer de material resistente ao manuseio" foi valorizado, por $38,46 \%$ no grupo das Enfermeiras-Che- 
fe/Diretora, contra $11,29 \%$ das(os) Enfermeiras(os).

Comparando as características indicadas pelas Enfermeiras - Chefe/Diretora com o Projeto no 04:12.1-00 de Equipo de Transfusão, Estéril e de Uso Único, observou-se que esses profissionais deixaram de indicar suas características contidas no referido projeto: "tubo flexível deve ter diâmetro não menos que $3 \mathrm{~mm}$ " e "o tubo nâo deve apresentar trincas, fendas e bolihas". No entanto, acredita-se que a primeira características referida determina uma especialidade singular que dificilmente seria lembrada, a não ser por manuseio constante da norma.

Observa-se que foram citados alguns aspectos que não se enquadram como itens de normas, tais como: "câmara de gotejamento com microfiltro para entrada de ar", "gotejador com gotejamento regulável (para que seja preciso)”, "embalagem de papel celofane", entre outros.

Como não existe norma específica para equipo de soro, a análise comparativa fica limitada ao considerar todos os detalhes levantados nas tabelas 5, 6, 7 e 8. Chama-se a atenção o fato de que esses profissionais indicaram, entre outras, duas características discordantes, que são: "todo equipo de soro deve ser dotado de uma entrada específica para injeção de medicamentos", 9,67\% das(os) Enfermeiras(os) e $23,07 \%$ das Enfermeiras - Chefe/Diretora, contra "equipo de soro não deve ser dotado de área de injeção de medicamentos", com 3,25\% e $15,38 \%$, respectivamente.

Estranha-se o fato de ter aparecido esta última característica, tendo em vista que a experiência mostra que a falta desse dispositivo dificulta a assistência de enfermagem, na medida que o número de pacientes que requerem medicamento endovenoso (de horário) é muito grande. A existência desse dispositivo, além de facilitar a administração, representa um ganho de tempo para a enfermagem e com probabilidade de diminuir a contaminação por manipulação excessiva.

Pelas observações realizadas nas Tabelas referentes ao equipo de soro, verifica-se dado o número importante de características levantadas que esses profissionais são conhecedores da maioria das características essenciais de qualidade do equipo de soro. Esperava-se, contudo, que os protetores de perfurador e do conector fossem indicados dentro do percentual estipulado para o estudo. Estranha-se que tais componentes tivessem percentagens abaixo principalmente quanto ao protetor de perfurador, já que ambos são componentes fundamentais no contexto do material.

Apresentamos, a seguir, as especificações do equipo de soro dentro do percentual estipulado para o presente estudo, mediante as opiniões levantadas pelas(os) Enfermeiras(os) e Enfermeiras-Chefe/Diretora entrevistadas (Fig. 2).

\section{CONCLUSÕES}

A população entrevistada demonstrou conhecimento quanto às características de qualidade dos materiais propostos para o estudo.

$\mathrm{O}$ número de citações de caracteres mínimos para cada material proposto revela o conhecimento da maioria desses caracteres, fundamentado na vivência da utilização dos materiais.

Nos requisitos essenciais de qualidade, ficou demonstrado que em alguns itens indicados pelas Enfermeiras(os) não representam características, e sim especificações e detalhes quanto ao tipo de material ou necessidade de um detalhamento maior.

A luz dos resultados e conclusões deste trabalho podemos recomendar que o conhecimento da qualidade dos materiais detectado entre as(os Enfermeiras(os) seja dirigido para:

- sistematizar as ações de enfermagem no processo de compra;

- estabelecer requisitos mínimos essenciais para os materiais;

- elaborar fichas ou registros das característicàs de qualidade dos materiais propostos: escalpe e equipo de soro para posterior aplicação prática nas instituições pesquisadas. 


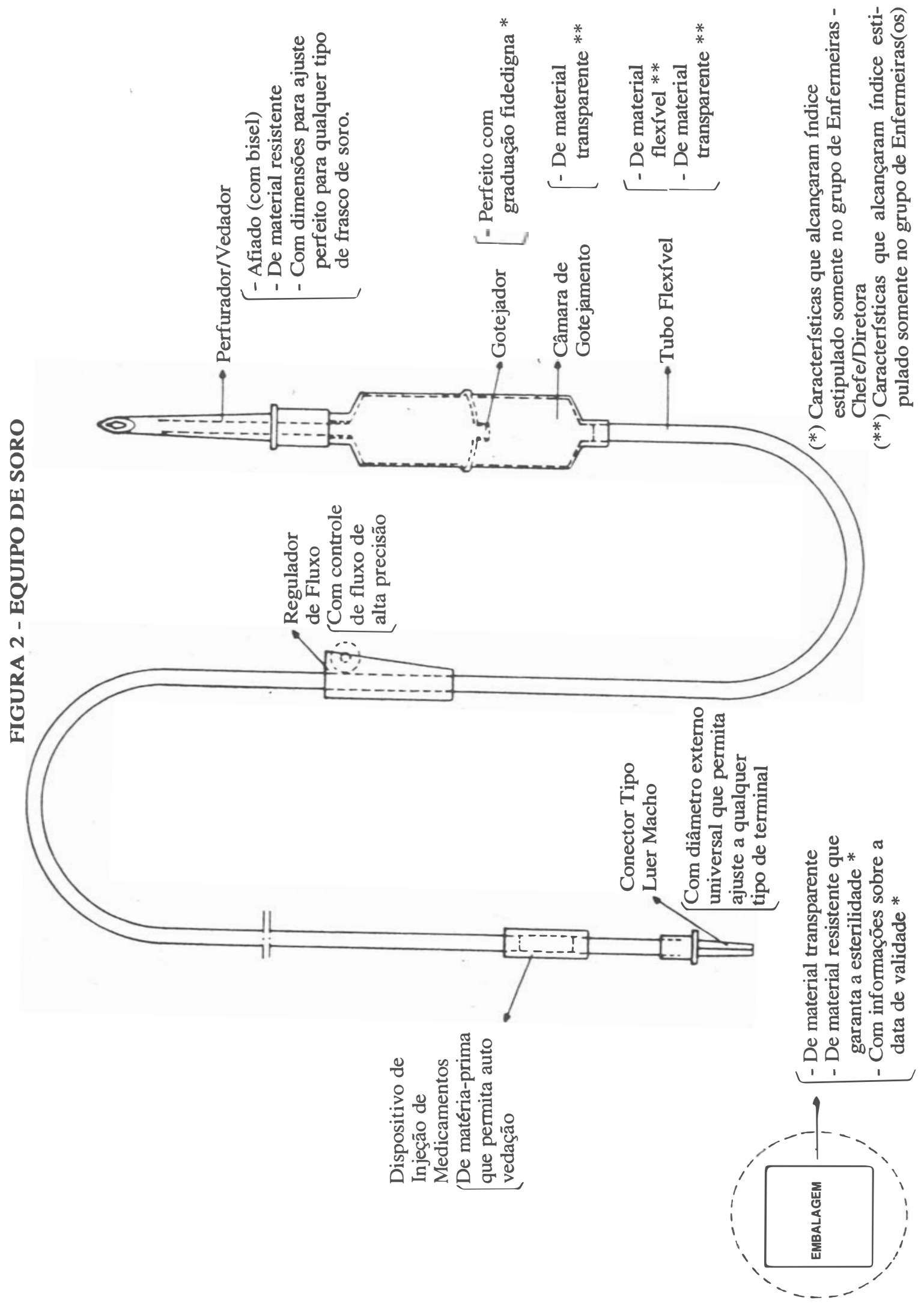

134 R. Bras. Enferm., Brasília, 44 (2/3): 124-135, abril/set. 1991 


\section{REFERÊNCIAS BIBLIOGRÁFICAS}

1. ARAÚJO, J.S. de,Almoxarifado e Almoxarifes. 4.ed. São Paulo: Atlas, 1966. 326p.

2. ASSOCIAÇĀO BRASILEIRA DE NORMAS TÉCNICAS. Comissão de Estudos de Seringas e Agulhas. Agulhas Hipodérmicas estéreis e de uso único; especificação: NBR-9259. Rio de Janeiro: 1966.

3. Comissão de Estudos de Seringas e Agulhas. Cânula de Escalpes: identificação do calibre por cor: NBR-9753. Rio de Janeiro: 1987. 3p.

4. Comissão de Estudos de Seringas e Agulhas. Equipo de transfusão, estéril e de uso único: projeto $n^{o}$ 04:12-1-00. Rio de Janeiro: 1988. 11p.

5. COSTA, H. de O.G. et alii. Participação em comissão técnica de material hospitalar. Rev. Bras. Enf., Brasília, 31(4): 525-536, out./dez. 1978.
6. ELKIS, J. Reesterilização de produtos descartáveis problemas e formas de controle. LAES/HAES, São Paulo, 6(2): 64-67, dez. 1984.

7. MAEDA, S. T. Escalpe, equipo de soro de seringa descartável. Critérios qualitativos para subsidiar a compra. São Paulo, 1988. 76p. (Dissertação de mestrado-Escola de Enfermagem da USP).

8. RIBEIRO, F.G. Cuidado na escolha e processamento do material utilizado na aspiração endo-traqueal. Trabalho apresentado no CONGRESSO NACIONAL DE CIRURGIA TORÁXICA, 4. ed. São Paulo, 1985. 8p.

9. SECAF, V. Papel da enfermeira na aquisição de material técnico. Rev. Bras. Enf., Brasília, 29(1):69-79, jan./mar., 1976.

10. SMI TH, T.C. Materiais management: a model product review. Nurs. Manag., Chicago, 16(3):51-54, mar.1985.

Prof Ma Miriam Lima da Mabraga Enfermelira Pslqulátrica - (OREN 12574

Mat. UFPB - 6593

\section{FORMULÁRIO PARA ENTREVISTA DE ENFERMEIRAS}

Entrevista no

Hospital:

Cargo Atual:

Unidade de Atuação:

Plantão: $\quad$ M ( ) $\quad$ T ( )

Data da Entrevista: Iń́cio: l'érmino: Tipo: Tempo de Exercício:

1. Como acontece a compra de materiais de consumo neste hospital ?

2. De que forma as(os) enfermeiras(os) têm participado nas etapas de processo de aquisição de materiais?

$-$

3. Na sua opinião as(os) enfermeiras(os) deveriam ter uma participação mais ativa no processo d $\epsilon$ aquisição de materiais? Justifique.

4. Na sua opinião como deveria acontecer a compra de materiais de consumo ?

5. Que característica você considera como qualidade que assegure o bom desempenho dos seguintes materiais? (Cite por componentes).

Escalpe:

Equipo de soro:

Seringa descartável: 